\title{
Smart Riders 3D Sebagai Game Pengenalan Rambu Lalu Lintas Berbasis Android
}

\author{
Febri Sulastianingsih ${ }^{1}$ dan R. Kartono ${ }^{2}$ \\ Jurusan Teknik Elektro, Universitas Negeri Semarang \\ Kampus Sekaran, Gunungpati, Semarang, 50229, Indonesia \\ febrisulastianingsih@gmail.com ${ }^{1}$, kartono_mpd@mail.unnes.ac.id ${ }^{2}$
}

\begin{abstract}
Android smartphone, one of the entertainment media that is used by many people for games. Besides being an entertainment media, games can be used as educational media, such as the introduction of traffic signs. Knowledge of traffic signs on motorists influences the occurrence of traffic accidents. Therefore, the introduction of traffic signs is one of the efforts in controlling traffic. This is because knowledge of traffic signs is currently lacking. In this study, it will present the making of a Smart Rider application that aims to introduce traffic signs to prospective drivers and drivers of motorized vehicles. The software development method used is Waterfall, which includes communication, planning, modeling, construction and deployment. Application testing uses material testing, functionality, usability and portability. Usability testing is done by media experts and users. Users in this study were taken from Kebumen Vocational High School 1 students. From the results of testing the application as a whole, shows that the application has a good function. The test results can be seen from the material test reaching 94.4\%, the user response reached $78.74 \%$, and the results of testing by media experts reached $87.5 \%$. Thus, the Smart Rider application is declared feasible to be used as a game for introducing Android-based traffic signs.
\end{abstract}

Keywords - Android, game, traffic sign, Waterfall

\begin{abstract}
Abstrak- Smartphone Android, salah satu media hiburan yang dimanfaatkan oleh banyak orang untuk game. Game selain sebagai media hiburan, dapat dimanfaatkan sebagai media edukasi, seperti game pengenalan rambu lalu lintas. Pengetahuan tentang rambu lalu lintas pada pengendara berpengaruh terhadap terjadinya kecelakaan lalu lintas. Maka dari itu, pengenalan rambu lalu lintas merupakan salah satu upaya dalam penertiban lalu lintas. Hal tersebut dikarenakan pengetahuan rambu lalu lintas saat ini masih kurang. Dalam penelitian ini, disajikan pembuatan aplikasi Smart Rider yang bertujuan untuk mengenalkan rambu lalu lintas kepada calon pengemudi dan pengemudi kendaraan bermotor. Metode pengembangan perangkat lunak yang digunakan yaitu Waterfall, meliputi communication, planning, modelling, construction, dan deployment. Pengujian aplikasi menggunakan uji materi, functionality, usability, dan portability. Pengujian usability dilakukan oleh ahli media dan pengguna. Dari hasil pengujian aplikasi secara keseluruhan, menunjukkan bahwa aplikasi memiliki fungsi yang baik. Hasil pengujian dapat dilihat dari uji materi mencapai $94,4 \%$, respon pengguna mencapai $78,74 \%$, dan hasil pengujian oleh ahli media mencapai $87,5 \%$. Dengan demikian, aplikasi Smart Rider dinyatakan layak digunakan sebagai game pengenalan rambu lalu lintas berbasis Android.
\end{abstract}

Kata kunci-Android, game, rambu lalu lintas, Waterfall

\section{Pendahuluan}

Perkembangan teknologi saat ini semakin pesat, khususnya dalam bidang teknologi informasi dan komunikasi. Salah satu teknologi yang populer adalah perangkat mobile seperti Smartphone. Kebutuhan akan smartphone semakin tinggi hal ini disebabkan karena sistem operasi yang terdapat pada smartphone adalah sistem operasi Android. Android digunakan di berbagai bidang seperti bidang perdagangan, politik, pendidikan dan lain-lain. Dalam bidang pendidikan, Android digunakan sebagai media pembelajaran. Terdapat keefektifan penggunaan Android sebagai media pembelajaran dengan hasil belajar yang didapat siswa [1]. Sedangkan bagi para remaja, smartphone sebagian besar digunakan untuk mengakses sosial media dan game [2].

Game merupakan salah satu media hiburan yang menjadi pilihan masyarakat untuk menghilangkan kejenuhan atau hanya sekedar untuk mengisi waktu luang. Pada perkembangannya game kini sudah sampai tiga dimensi (3D), yang sebelumnya hanya sampai dua dimensi (2D). Game 3D juga banyak digunakan sebagai simulasi dalam pendidikan, kedokteran, politik, dan lain-lain.

Game sendiri dapat digunakan sebagai media untuk melatih kemampuan daya pikir dan memperkenalkan materi agar lebih menarik [3]. Sebagai contoh penelitian [4], pembelajaran Starter Experiment Approach (SEA) berbantuan game dapat meningkatkan hasil belajar dan mengembangkan 
karakter siswa. Teknologi game 3D berbasis Android dapat dimanfaatkan sebagai media hiburan dan pembelajaran, salah satunya dapat digunakan sebagai media dalam mengenalkan rambu lalu lintas.

Rambu lalu lintas merupakan salah satu pengetahuan yang sangat penting bagi pengguna jalan dalam menertibkan lalu lintas. Hal ini dikarenakan dapat mengurangi permasalahan lalu lintas seperti kemacetan, kecelakaan lalu lintas, dan permasalah lalu lintas lainnya yang dapat merugikan orang lain. Seperti yang tertera dalam Undang-Undang Republik Indonesia nomor 22 tahun 2009 tentang Lalu Lintas dan Angkutan Jalan, bahwa pengetahuan dalam berkendara harus diutamakan untuk keselamatan dalam berkendara.

Kecelakaan lalu lintas di jalan raya diakibatkan atau diawali oleh perilaku pengemudi yang melanggar aturan lalu lintas yang ada, seperti mengemudi dengan kecepatan tinggi serta tidak hati-hati, kemudian tidak memiliki surat ijin mengemudi [5]. Faktor manusia, merupakan faktor dominan penyebab kecelakaan lalu lintas, karena hampir semua kecelakaan lalu lintas yang terjadi disebabkan oleh pelanggaran lalu lintas [6]. Faktor manusia tersebut meliputi perilaku, pengetahuan serta keterampilan di jalan raya. Pengetahuan tentang rambu lalu lintas pada pengendara berpengaruh terhadap terjadinya kecelakaan lalu lintas. Hasil penelitian [7] menyebutkan bahwa kurangnya sosialisasi dan kesadaran untuk belajar mengenai aturan berlalu lintas menjadi salah satu penyebab minimnya pengetahuan serta pemahaman pelajar.

Pada penelitian [8] telah dibuat aplikasi multimedia pembelajaran rambu-rambu lalu lintas berbasis Android. Aplikasi memiliki animasi menarik yang dilengkapi dengan kuis soal rambu-rambu lalu lintas yang disajikan dengan tampilan dua dimensi. Aplikasi cocok dan memenuhi syarat bagi pengguna yang ingin mengetahui rambu lalu lintas dan mengerjakan soal tes SIM. Pada penelitian [9] telah dibuat aplikasi panduan sosialisasi keselamatan lalu lintas dengan Android dan menggunakan metode Waterfall dalam pembuatannya. Hasil yang diperoleh aplikasi tersebut mendapatkan skala sangat baik, sehingga layak digunakan sebagai media panduan sosialisasi keselamatan lalu lintas.

Pada penelitian [10] telah dibuat game edukasi berbasis Android untuk membantu para pengendara bermotor dalam mempelajari dan menghafal arti rambu lalu lintas. Game berisi soal terkait rambu lalu lintas sebanyak 84 soal yang dibagi ke dalam tiga level yaitu mudah, sedang, dan sulit. Kemudian penelitian [11] menembangkan aplikasi pengetahuan tanda lalu lintas berbasis Android. Tujuannya sebagai sarana pengguna untuk belajar, mengetahui rambu lalu lintas dan peraturan mengemudi di Thailand menggunakan aplikasi mobile. Dalam aplikasi tersebut tersedia modul serta soal yang harus dikerjakan oleh pengguna serta memiliki tampilan dua dimensi.

Berdasarkan kajian penelitian yang telah dilakukan, pembuatan aplikasi mengenai rambu lalu lintas telah banyak dilakukan. Akan tetapi, aplikasi tersebut masih memiliki tampilan 2 dimensi. Oleh karena itu, pada penelitian ini akan dibuat aplikasi berupa game 3 dimensi berbasis Android sebagai media pengenalan rambu lalu lintas bagi calon pengemudi dan pengemudi kendaraan bermotor yang diberi nama "Smart Riders". Pemilihan 3 dimensi dilakukan agar aplikasi terlihat lebih interaktif dan menarik untuk pengguna.

\section{Metode PEnelitian}

Metode yang digunakan dalam pengembangan aplikasi ini adalah Waterfall. Kelebihan metode Waterfall adalah memungkinkan untuk departementasi dan kontrol. Tahapan dimulai dari tahap komunikasi (communication), lanjut ke tahapan-tahapan perencanaan (planning), pemodelan (modeling), penulisan kode (code), serta uji coba (testing) [12].

\section{A. Tahap Komunikasi (Communication)}

Sebelum memulai pekerjaan yang sifatnya teknik, diperlukan adanya komunikasi, dalam hal ini komuikasi dilakukan dengan dosen pembimbing demi memahami dan mencapai tujuan yang ingin dicapai dari aplikasi "Smart Riders". Hasil dari komunikasi adalah analisis kebutuhan berupa kebutuhan software, materi, dan kebutuhan pengembangan aplikasi lainnya. Kebutuhan data tambahan diambil dari jurnal, artikel, dan internet.

\section{1) Analisis Masalah}

Analisis masalah dilakukan untuk menganalisis permasalahan terkait pentingnya pengetahuan rambu lalu lintas bagi pengguna jalan dan media yang menarik sebagai sarana untuk menambah pengetahuan rambu lalu lintas.

\section{2) Analisis Kebutuhan Materi dan Data}

Materi dan data yang diperlukan dalam pengembangan game Smart Riders adalah materi rambu lalu lintas. Materi didapat dari berbagai jurnal, buku maupun undang-undang lalu lintas.

\section{3) Analisis Kebutuhan Software}

Berikut software yang digunakan dalam pembuatan game Smart Riders :

- Windows 8.1 Pro sebagai sistem operasi.

- Unity 3D untuk membuat game 3D.

- Adobe Photoshop CS3 untuk membuat desain gambar.

4) Analisis Kebutuhan Hardware

Perangkat keras (hardware) yang diperlukan dalam proses pembuatan game Smart Riders adalah perangkat komputer (laptop) dengan spesifikasi sebagai berikut:

- Processor : Intel(R) Celeron(R) CPU 1000M @ $1.80 \mathrm{GH}_{\mathrm{z}}$

- RAM : 4GB

- Harddisk : $500 \mathrm{~GB}$

- Monitor : 14.0"' dengan resolusi 1366x768

- Android minimal Jelly Bean, sebagai sistem operasi perangkat mobile 


\section{B. Tahap Perencanaan (Planning)}

Pada tahap planning atau perencanaan dilakukan dengan cara membuat penjadwalan proses pengembangan yang meliputi estimasi waktu yang dibutuhkan dalam mengembangkan aplikasi. Jadwal pengembangan dimulai dari tahap analisis kebutuhan hingga pengujian, termasuk didalamnya adalah pembuatan fitur aplikasi.

\section{Tahap Pemodelan (Modeling)}

Pada tahap ini peneliti akan membuat perancangan desain game Smart Riders yang meliputi desain aplikasi dan perancangan user interface. Diagram blok Game Smart Riders ditunjukkan pada Gambar 1.

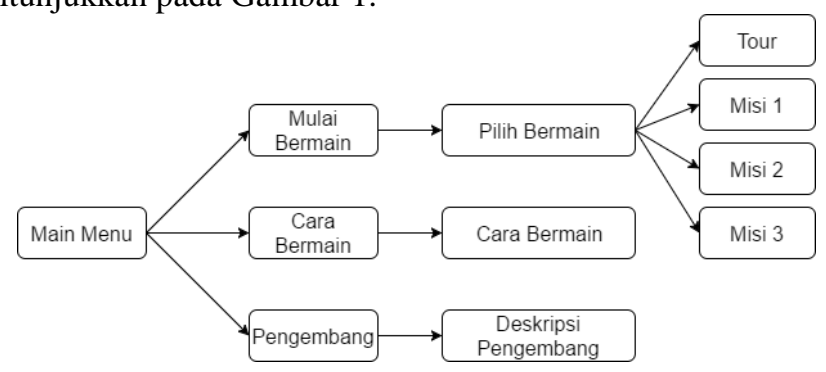

Gambar 1. Diagram blok Game Smart Riders

Game Smart Riders memiliki menu utama yang berisi menu Mulai, Cara Bermain, dan Pengembang. Menu mulai akan mengarah pada halaman pilih bermain, dimana akan terdapat empat pilihan yaitu tour, misi 1, misi 2, dan misi 3. Pada tour akan berisi pengenalan rambu lalu lintas dan pada misi 1-3 merupakan game mematuhi rambu lalu lintas dan menjawab setiap pertanyaan dengan ketentuanketentuan yang ditunjukkan pada Gambar 2 untuk mendapatkan skor.

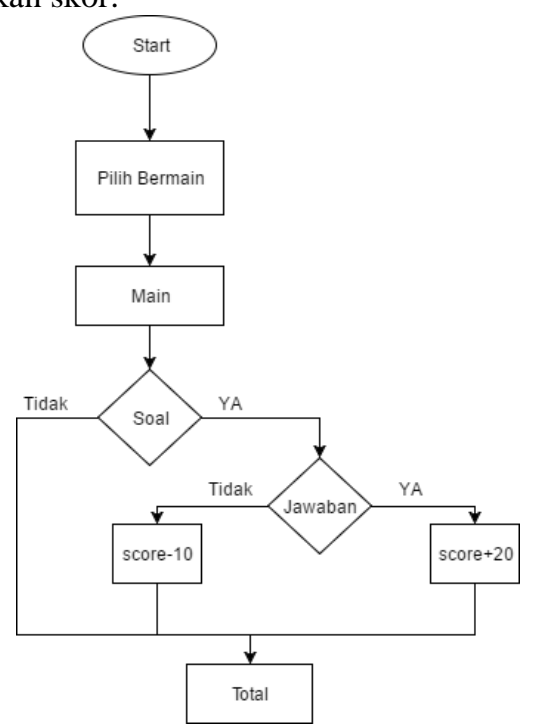

Gambar 2. Flowchart Skor Pada Game Smart Riders

Ketentuan-ketentuan tersebut meliputi:

- Jika menjawab soal dengan benar, maka akan mendapat poin 20. Jika menjawab soal salah, maka poin akan berkurang 10.
- Jika bertemu rambu lalu lintas, dan mengarahkan mobil tidak sesuai dengan rambu lalu lintas yang ada, maka akan ada peringatan yang berisi jalan yang dilalui salah.

- Misi dikatakan selesai, jika pengguna telah mengarahkan mobil ke tempat tujuan yang sesuai pada misi tersebut.

Terdapat menu Cara Bermain yang mengarahkan bagaimana cara bermain serta ketentuan-ketentuan yang berlaku dalam permainan. Menu Pengembang akan memberi tahu deskripsi singkat terkait pengembang.

\section{Penulisan kode (code)}

Penulisan kode merupakan proses membuat kode. Coding atau pengkodean merupakan penerjemahan desain bahasa yang biasa dikenali oleh komputer. tahap inilah yang merupakan tahap secara nyata dalam menerjemahakan suatu software, artinya penggunaan perangkat komputer akan dimaksimalkan pada tahap ini.

Pada tahap ini dilakukan pembuatan aplikasi "Smart Riders" 3D menggunakan software Unity 3D dan selanjutnya build aplikasi ke device Android. Bahasa pemrograman yang digunakan adalah bahasa pemrograman $\mathrm{C \#}$.

E. Tahap uji coba (testing)

\section{1) Uji Materi}

Uji materi dilakukan dengan menggunakan kuesioner. Kuesiner diberikan kepada ahli materi dalam bidang lalu lintas yang dipilih untuk melakukan uji materi.

\section{2) Uji Kelayakan perangkat lunak}

Uji kelayakan perangkat lunak meliputi aspek functionality suitability, usability, dan portability installability. Aspek tersebut mengacu pada faktor-faktor kualitas pernagkat lunak menurut quality factors ISO 9126.

\section{HASIL DAN PEMBAHASAN}

A. Hasil

Deskripsi data yang dibahas pada penelitian ini berupa deskripsi hasil antarmuka produk, hasil pengujian terhadap ahli materi, dan uji kelayakan perangkat lunak. Pada uji kelayakan perangkat lunak, terdapat tiga aspek yaitu functionality (uji black-box), usability (uji media dan respon), dan portability (uji instalasi aplikasi ke beberapa Os Android yang berbeda). Beberapa tampilan antar muka produk ditunjukkan pada Gambar 3 hingga Gambar 7.

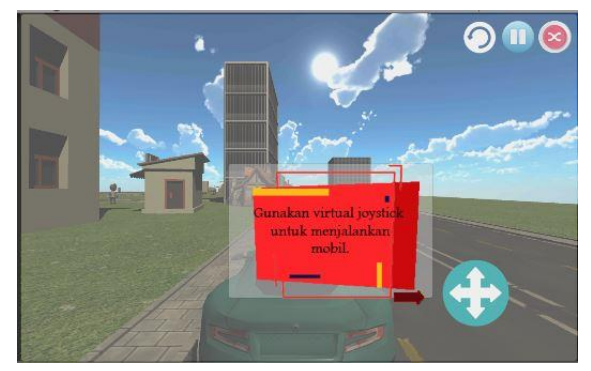

Gambar 3. Petunjuk kontrol 


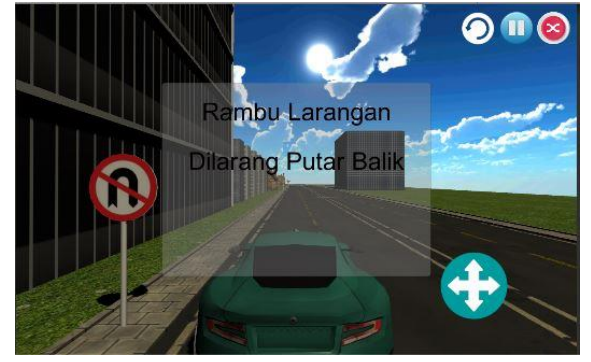

Gambar 4. Tampilan materi rambu lalu lintas

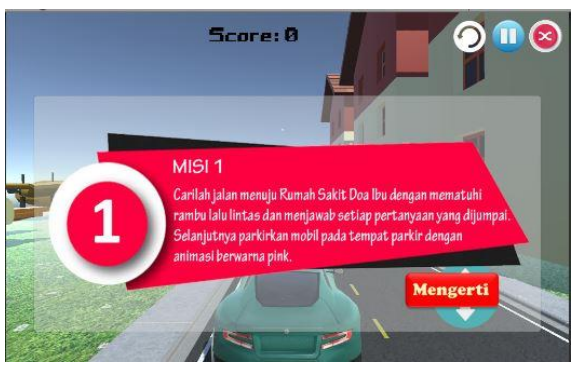

Gambar 5. Tampilan halaman misi

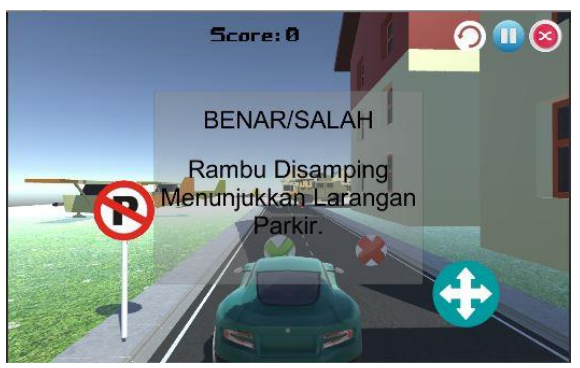

Gambar 6. Tampilan soal

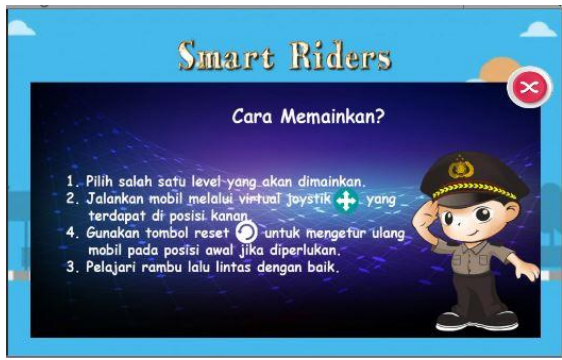

Gambar 7. Halaman cara bermain

Gambar 3 menampilkan petunjuk kontrol yang digunakan untuk menunjukkan fungsi setiap tombol pada game. Gambar 4 menampilkan materi rambu lalu lintas. Gambar 5 menampilkan halaman awal permainan pada setiap misi yang berisi petunjuk untuk menyelesaikan permainan. Gambar 6 menampilkan soal mengenai rambu lalu lintas, yang harus dijawab dengan cara mengarahkan mobil ke tanda benar (V) atau salah (X). Gambar 7 menampilkan halaman cara bermain game Smart Rider.

Aplikasi pengenalan rambu lalu lintas "Smart Riders" berbasis Android dapat digunakan sebagai aplikasi pengenalan rambu lalu lintas. Hal ini karena aplikasi menarik dalam memberikan pengetahuan terkait materi rambu lalu lintas jalan bagi anak-anak hingga orang dewasa. Smart Riders dibuat dengan tampilan tiga dimensi dan menyerupai aslinya agar lebih mudah untuk dipahami. Aplikasi memiliki beberapa sub menu yaitu sub menu untuk mengenalkan rambu lalu lintas, dan tiga sub menu berupa permainan dengan misi yang berbeda-beda terkait rambu lalu lintas.

Pengujian yang diambil terdiri dari aspek materi untuk memvalidasi kesesuaian obyek 3D dengan materi yang terkandung pada aplikasi, dan pengujian perangkat lunak berupa aspek functionality, usability serta portability.

Pengujian materi lebih difokuskan kepada kesesuaian objek 3D dengan tema materi yaitu rambu lalu lintas. Validasi materi dilakukan oleh Dinas Perhubungan Kab. Kebumen bidang lalu lintas. Hasil dari validasi materi dapat dilihat pada Tabel I.

TABEL I. HASIL DAN VALIDASI MATERI

\begin{tabular}{|l|l|c|}
\hline No & Aspek Penilaian & Skor (\%) \\
\hline 1 & Kesesuaian Materi & $94,4 \%$ \\
\hline 2 & Kemampuan & $87,5 \%$ \\
\hline 3 & Ketepatan & $91,67 \%$ \\
\hline 4 & Kemudahan & $86,1 \%$ \\
\hline \multicolumn{2}{|l|}{ Rata-rata } & $89,91 \%$ \\
\hline \multicolumn{2}{|l|}{ kriteria } & Sangat Valid \\
\hline
\end{tabular}

Data pada Tabel I menunjukkan persentase penilaian dari ahli materi meliputi aspek kesesuaian materi $(94,4 \%)$, aspek kemampuan $(87,5 \%)$, aspek ketepatan $(91,67 \%)$, dan aspek kemudahan $(86,91 \%)$. Berdasarkan data tersebut maka persentase penilaian ahli materi sebesar $89,91 \%$, yang dikategorikan "Sangat Valid". Interval penilaian dikatakan "Sangat Valid" antara $81,25 \%<$ skor $\leq 100 \%$.

Pengujian functionality suitability dilakukan secara mandiri dengan menggunakan black box yang disesuaikan dengan fungsionalitas pada aplikasi Smart Riders. Hasil pengujian black box menunjukkan bahwa semua fungsi yang ada dapat berjalan dengan baik sesuai dengan use case yang telah dibuat dengan persentase $100 \%$. Oleh karena itu, aplikasi Smart Riders dinyatakan sangat baik dari segi functionlity suitability.

Pengujian usability dilakukan dengan melakukan pengujian pada dua ahli media dan siswa kelas XI dari SMK N 1 Kebumen, dengan menggunakan kuisioner. Terdapat 35 siswa di setip kelas, dan hanya diambil sampel 1 kelas yaitu kelas Multimedia 1. Dari 35 siswa kelas XI Multimedia 1 yang ada, hanya diambil sampel sebanyak 29 siswa yang mengisi kuisioner. Persentase kelayakan aspek usability dari ahli media secara keseluruhan adalah $87,5 \%$, dan dinyatakan sangat baik.

Aspek pengujian usability yang diujikan kepada siswa mengacu pada indikator understandbility, learnability, dan attractivenes. Hasil dari pengujian indikator-indikator tersebut dapat dilihat pada Tabel II. 
TABEL II. HASIL PENGUJIAN USABILITY

\begin{tabular}{|l|l|c|}
\hline No & \multicolumn{1}{|c|}{ Aspek Penilaian } & Skor (\%) \\
\hline 1 & Understandbility & $77,59 \%$ \\
\hline 2 & Learntability & $81,32 \%$ \\
\hline 3 & Attractivenes & $70,30 \%$ \\
\hline Rata-rata & $78,74 \%$ \\
\hline Kriteria & Layak \\
\hline
\end{tabular}

Dari data hasil uji coba pengguna pada Tabel II dapat disimpukan bahwa secara keseluruhan aplikasi Smart Riders sudah memenuhi kriteria kelayakan yang baik, dan dapat digunakan sebagai aplikasi pengenalan rambu lalu lintas berbasis Android. Hal itu ditunjukkan dari perolehan persentase pada indikator understandbility sebesar 77,59\%, learntability sebesar $81,32 \%$, dan attractivenes sebesar $77,30 \%$. Rata-rata persentase secara keluruhan yaitu 78,74\% yang artinya aplikasi Smart Riders dikategorikan "Layak". Kategori aplikasi dikatakan "Layak" jika interval persentase antara $62,5 \%<$ skor $\leq 81,25 \%$.

Aspek pengujian portability menggunakan beberapa smartphone, seperti pada Tabel III. Pengujian dilakukan secara langsung menghasilkan persentase $100 \%$, yang dapat dikatakan sangat layak. Sehingga aplikasi Smart Riders memenuhi aspek portability.

TABEL III. SPESIFIKASI SMARTPHONE

\begin{tabular}{|c|l|c|}
\hline No & Perangkat & Spesifikasi \\
\hline 1 & SAMSUNG & Android 4.4.4 (Kitkat) \\
& GALAXY V PLUS & RAM 512 MB \\
& & Layar 4.0 inchi \\
& & Prosesor Dual-Core 1.2 Ghz \\
\hline 2 & OPPO NEO 7 & Android 5.1 (Lolipop) \\
& & RAM 1 GB \\
& & Payar 5.0 inchi \\
\hline 3 & AZUS ZENFONE 2 & Android 5.0 (Lolipop) \\
& & RAM 4 GB \\
& & Layar 5.5 inchi \\
\hline 4 & OPPO A3S & Prosesor Intel Atom Z3580 \\
& & Android 8.1 (Oreo) \\
& & RAM 2 GB \\
& & Layar 6.2 inchi \\
& & Prosesor Qualcomm Snapdragon \\
\hline
\end{tabular}

Dari penelitian ini dihasilkan sebuah aplikasi Smart Riders 3D berbasis Android yang mampu digunakan sebagai aplikasi pengenalan rambu lalu lintas dengan tampilan yang menarik. Dimana setiap obyek yang terdapat pada aplikasi berupa obyek 3D, sehingga obyek terlihat lebih nyata. Hal tersebut menjadi kelebihan dari aplikasi Smart Riders.

\section{B. Pembahasan}

Aplikasi Smart Riders memiliki tampilan tiga dimensi yang meliputi obyek rambu lalu lintas, mobil, jalan, bangunan dan obyek pendukung lain. Hal ini mendukung aplikasi agar terlihat lebih nyata, sehingga mempermudah dalam pemahaman materi. Berbeda halnya dengan penelitian [8] dan [11] yang masih menggunakan tampilan dua dimensi. Dimana tampilan dua dimensi tidak menyediakan objek secara detail, dan tampilan hanya dapat dilihat dari satu arah yaitu tampak depan.

Jika pada penelitian [10] pertanyaan disajikan secara bergantian sampai jumlah pertanyaan selesai, pertanyaan pada aplikasi Smart Riders berupa pertanyaan benar/salah. Dimana pertanyaan dibuat sesuai dengan kondisi jalan atau rambu lalu lintas pada saat itu. Sehingga dalam menjawab setiap pertanyaan harus diikuti dengan sebuah tindakan yang sesuai. Seperti tampilan pada Gambar 8 dan Gambar 9.

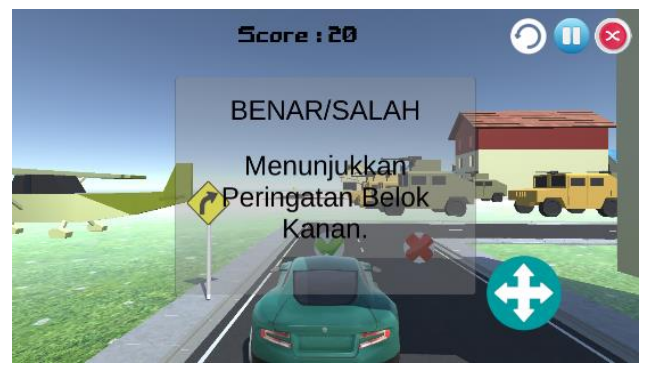

Gambar 8. Menampilkan soal dalam bentuk benar atau salah terkait rambu lalu lintas.Dalam menjawab soal, harus mengarahkan mobil pada jawaban yang dipilih

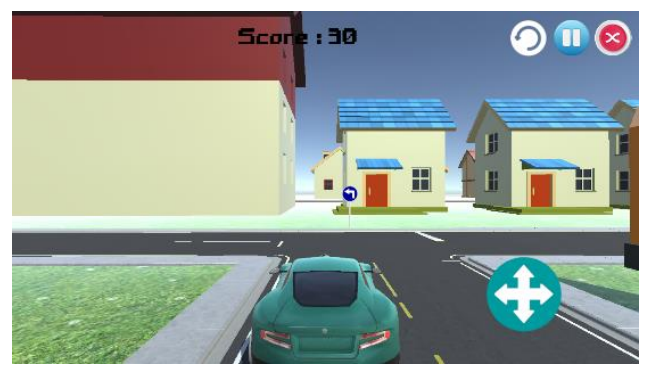

Gambar 9. Menampilkan rambu lalu lintas, dimana pengguna harus mematuhi rambu lalu lintas dengan menjalankan mobil sesuai rambu lalu lintas yang ada

Saat pengambilan data responden, para pengguna mengungkapkan bahwa aplikasi tersebut membantu untuk mendapatkan informasi mengenai arti rambu lalu lintas. Kemudian jika dilihat dari segi isi materi, menu, tampilan dan penggunaan sangat menarik dan mudah untuk dipahami oleh pengguna. Pengguna aplikasi Smart Riders ditujukan untuk seluruh masyarakat baik anak-anak hingga orang dewasa.

\section{PENUTUP}

Pengembangan aplikasi "Smart Riders" telah dibuat. Hasil pengujian perangkat lunak "Smart Riders" masuk dalam kategori "Layak". Nilai persentase hasil pengujian ahli materi untuk setiap aspek yaitu kesesuaian materi 94,4\%, kemampuan $87,5 \%$, ketepatan $91,67 \%$, dan kemudahan $86,1 \%$. Persentase total dari uji ahli materi yaitu $89,91 \%$ (Sangat Layak). Pengujian ahli media memperoleh persentase 87,5\% (Sangat Layak). Persentase pengujian perangkat lunak aspek functionality 100\% (Sangat Layak), usability 78,74\% (Layak), dan portability $100 \%$ (Sangat Layak). Saran pengembangan aplikasi adalah tombol kontrol permainan yang lebih kompleks dan penambahan referensi untuk materi yang disajikan sehingga menjadi lebih lengkap. 


\section{REFERENSI}

[1] S. Muyaroah dan M. Fajartia, "Pengembangan Media Pembelajaran Berbasis Android dengan menggunakan Aplikasi Adobe Flash CS 6 pada Mata Pelajaran Biologi Abstrak", Innov. J. Curric. Educ. Technol., vol. 6, no. 2, pp. 79-83, 2017.

[2] M. Muflih, H. Hamzah, dan W. A. Puniawan, "Penggunaan Smartphone dan Interaksi Sosial pada Remaja di SMA Negeri I Kalasan Sleman Yogyakarta", Idea Nurs. J., vol. VIII, no. 1, pp. 12-18, 2017.

[3] D. W. Putra, A. P. Nugroho, dan E. W. Puspitarini, "Game Edukasi Sebagai Media Pembelajaran Pendidikan Anak Usia Dini”, Inform, vol. 1, no. 1, pp. 1-8, 2016.

[4] D. Bestari, D. Yulianti, dan P. Dwijananti, "Pembelajaran Fisika Menggunakan SEA Berbantuan Games untuk Mengembangkan Karakter Siswa SMP", Unnes Physics Education Journal, vol. 3, no. 1, 2014.

[5] A. Dharma, "Identifikasi Kecelakaan Lalu Lintas (Study Kasus Jalan Dalu-Dalu sampai Pasir Pengaraian)", J. Mhs. Tek., vol. 1, no. 1, pp. 1-6, 2014.

[6] C. Setiawan dan R. Hafrizal, "Media Pembelajaran Interaktif Pengenalan Rambu-Rambu Lalu Lintas untuk Calon Pengendara di Jalan Raya Menggunakan Flash", J. LPKIA, vol. 1, no. 1, pp. 22-27, 2014.
[7] F. Wulandari, "Pemahaman Pelajar Tentang Disiplin Berlalu Lintas (Studi di SMK Kesehatan)", ejournal Sosiatri - Sosiol., vol. 3, no. 3, pp. 52-64, 2015.

[8] R. Wardan dan D. Kurniadi, "Aplikasi Multimedia Pembelajaran Rambu Lalu Lintas Berbasis Android", $J$. Algoritm., vol. 14, no. 2, pp. 1-8, 2017.

[9] K. Sa'adah, R. Kartono, dan A. Mulwinda, "Aplikasi Panduan Sosialisasi Keselamaan Lalu Lintas "Road Safety" Menggunakan Phonegap dengan Android", Prosiding SINTAK, pp. 169-175, 2017.

[10] I. Bagus, K. Adi, P. W. Buana, dan A. A. K. A. C. W, "Game Edukasi Rambu Lalu Lintas Berbasis Android", Merpati, vol. 3, no. 3, pp. 190-201, 2015.

[11] S. Janpla, P. Bumrugrad, and K. Kularbphettong, "Developing a Traffic-Sign Knowledge Application on Android System", Procedia - Soc. Behav. Sci., vol. 191, pp. 680-685, 2015.

[12] R. S. Pressman, Software engineering: a practioner's approach 8th ed, New York: McGraw-Hill Companies, 2010. 